\section{Self-care among patients enrolled in a self-monitoring blood glucose program}

\author{
Autocuidado de pacientes inseridos em um programa \\ de automonitorização da glicemia capilar no domicílio \\ Autocuidado de pacientes incluidos en un programa \\ de automonitorización de la glucosa sanguínea en domicilio
}

\author{
Vivian Saraiva Veras ${ }^{\mathrm{a}}$ \\ Manoel Antônio dos Santos ${ }^{b}$ \\ Flavia Fernanda Luchetti Rodriguesc \\ Clarissa Cordeiro Alves Arrelias ${ }^{c}$ \\ Tatiane Aparecida Martins Pedersolic \\ Maria Lúcia Zanettid
}

\begin{abstract}
This cross-sectional study checks specific self-care activities of patients with diabetes mellitus enrolled in a self-monitoring blood glucose program from August to December 2012 in two Primary Health Care units in the interior of São Paulo, Brazil. The sample was composed of 74 female and male individuals, aged 18 years old or older. The Summary of Diabetes Self-Care Activities Questionnaire was used. It contains six dimensions: general diet, specific diet, physical activity, blood glucose monitoring, foot care, medication usage, plus three items about smoking. Eight out of the 15 self-care activities were within desirable levels, namely: healthy diet, not eating sweets, blood glucose testing and as frequently as recommended, drying between toes after washing feet, and taking medications (three items). The results enabled the identification of gaps in specific self-care activities among patients with diabetes mellitus. Descriptors: Self-care. Diabetes Mellitus. Blood glucose self-monitoring. Nursing.
\end{abstract}

\section{RESUMO}

Estudo transversal com o objetivo de verificar as atividades de autocuidado específicas de pacientes com diabetes mellitus inseridos em programa de automonitorização da glicemia capilar, de agosto a dezembro de 2012, em duas unidades básicas de saúde do interior paulista. A amostra foi composta por 74 sujeitos de ambos os sexos, com idade igual ou superior a 18 anos. Utilizou-se Questionário de Atividades de Autocuidado com Diabetes, contendo seis dimensões: alimentação geral, alimentação específica, atividade física, monitorização da glicemia, cuidados com pés, uso de medicamento, acrescidos de três itens sobre tabagismo. Das 15 atividades de autocuidado, oito estavam dentro do padrão desejável, destacando-se: alimentação saudável, não ingerir doces, avaliar o açúcar no sangue e o número de vezes, secar os espaços interdigitais depois de lavar os pés e tomar medicamentos (três itens). Os resultados obtidos possibilitaram identificar as lacunas das atividades de autocuidado específicas de pacientes com diabetes mellitus.

Descritores: Autocuidado. Diabetes Mellitus. Automonitorização da glicemia. Enfermagem.

\section{RESUMEN}

Este estudio transversal objetivó verificar las actividades de autocuidado específicas para pacientes con diabetes mellitus insertados en el programa de automonitorización de glucosa sanguínea, de agosto a diciembre 2012 en dos unidades básicas de salud en el interior paulista. La muestra consistió en 74 sujetos de ambos sexos, con edad igual o superior a 18 años. Se empleó el Cuestionario de Actividades de Autocuidado con Diabetes, que contiene seis dimensiones: dieta general, dieta específica, actividad física, monitorización de glucosa sanguínea, cuidado con los pies, uso de fármacos y evaluación del tabaquismo. De las 15 actividades de autocuidado, ocho eran dentro de la norma deseable, a saber: la alimentación saludable, no comer dulces, evaluar el nivel de azúcar en la sangre y el número de veces, seca entre los dedos después de lavarse los pies y tomar medicamentos, además de tres artículos sobre el tabaquismo. Los resultados permitieron identificar lagunas específicas en las actividades de autocuidado de los pacientes con diabetes mellitus. Descriptores: Autocuidado. Diabetes Mellitus. Automonitorización de la glucosa sanguínea. Enfermería.
D0l: http://dx.doi.org/10.1590/19831447.2014.04.47820

RN. PhD in Sciences, University of São Paulo at Ribeirão Preto, College of Nursing, Graduate Nursing Program. Ribeirão Preto, SP, Brazil.

${ }^{b}$ Psychologist. PhD in Psychology. Associate Professor, University of São Paulo at Ribeirão Preto, Faculty of Philosophy, Science and Letters, Department of Psychology. Ribeirão Preto, SP, Brazil

' RN. PhD candidate in Sciences, University of São Paulo at Ribeirão Preto, College of Nursing, Graduate Nursing Program. Ribeirão Preto, SP, Brazil

${ }^{d}$ RN. PhD in Nursing. Associate Professor, University of São Paulo at Ribeirão Preto, College of Nursing, Department of General and Specialized Nursing. Ribeirão Preto, SP, Brazil. 


\section{DINTRODUCTION}

Diabetes Mellitus (DM) is a complex chronic condition due to the multiple elements involved in its treatment such as: regularly maintaining a healthy diet; exercising as a habit incorporated in the patient's routine; self-monitoring of blood glucose; and taking medication that is not always easy to administer due to pharmacokinetic and pharmacodynamics factors. In this sense, self-care has been explored in the literature as an important construct in the consolidation of lifestyle modifications, which are necessary to achieving good metabolic control(1-4).

In regard to self-monitoring of blood glucose (SMBG), in 2007, the Ministry of Health established a list of medications and supplies provided by the Brazilian Health System (SUS) to patients with DM to self-monitor blood glucose. To be included in this public policy, patients must be enrolled in the programa de AMGC no domicilio [SMBG at home program]. This program is intended to assess monitoring of blood glucose as performed by patients with DM at home according to adherence to their treatment recommendations. This assessment's purpose is to support therapeutic adjustments in order to achieve improved glycemic control, preventing acute and/or chronic complications ${ }^{(5)}$.

Nonetheless, to effectively achieve results that accrue from SMBG, patients with DM should incorporate self-care activities into the set of demands required to maintain metabolic control. Self-care refers to activities people perform with responsibility and efficacy to benefit their lives, health and well-being ${ }^{(6)}$. One's age, experiences and lifestyle, education, culture, gender, attitudes, and systems of beliefs and values directly affect one's ability to self-care ${ }^{(7-8)}$.

There are various studies in the literature that identify factors related to self-care behaviors of patients with DM using generic instruments ${ }^{(9-10)}$. There is, however, a lack of studies using specific instruments ${ }^{(2,4)}$. Among the specific instruments used to assess self-care activities among people with DM, the Summary of Diabetes Self-Care Activities Questionnaire (SDSCA) stands out.

Brazilian studies assessing self-care activities using specific instrument are incipient( ${ }^{(2-4)}$ because the translation, cross-cultural adaptation and validation of SDSCA became available in 2010 (11). Additionally, there are no studies in the Brazilian context assessing self-care activities among patients with DM enrolled in SMBG at home programs.

Acknowledging that patients with diabetes have particularities due to treatment complexity, the use of a specific instrument such as SDSCA can contribute to a more accurate diagnosis of self-care activities. In this sense, the planning of interventions will be based on reliable data concerning how well patients adhere to the recommendations of healthcare providers. This information is valuable for planning effective healthcare actions to manage DM.

Recognizing the importance of identifying self-care activities among patients enrolled in the SMBG at home program, this study's aim was to identify the specific selfcare activities performed by patients with DM, enrolled in this program.

\section{$\square$ METHOD}

Cross-sectional study conducted in two Primary Health Care (PHC) units in the East District of Ribeirão Preto Health Department, from August to December 2012. These health units were selected because they are located in the city's East District and are linked to the university and also because of the participation of professors and undergraduate and graduate students in research and extension activities.

The convenience sample was composed of 74 individuals with type 2 DM who agreed to participate in an educational group on diabetes concerning self-monitoring of blood glucose. The groups were composed of 12 to 13 patients who met weekly for 60 minutes over the course of 12 weeks. The teaching strategy used was group discussion. The topics discussed included how the body and diabetes work; healthy diet and physical exercise; medication scheme and blood glucose testing; and how to achieve goals to manage the disease.

The SMBG program was implemented in 2005 as a continuous project in accordance with city policy; however, it did not include an educational group. The patients enrolled in the SMBG receive a glucometer, lancing device, and reagent strips in number sufficient for them to test blood glucose at home according to the recommended number of times per month.

The study included both female and male patients with DM, aged 18 years old or older, originating from Ribeirão Preto or surrounding cities, monitored through the SMBG at home program in the two selected health units, and who presented no understanding deficits that would impede completing the instrument.

Two instruments were used to collect data: a form addressing sociodemographic data and the Summary of Diabetes Self-Care Activities (SDSCA). The form included the following sociodemographic data: sex, age (complete years), schooling, family income, occupation, along with the clinical variables: time since diagnosis, treatment to control DM and comorbidities.

SDSCA is a self-applied questionnaire to specifically assess self-care activities concerning diabetes. It was orig- 
inally developed in English and its name in Portuguese is Questionário de Atividades de Autocuidado com o Diabetes (QAD). The SDSCA was adapted to Portuguese in Portu$\mathrm{gal}^{(12)}$, in which version, the Cronbach's alpha ranged from 0.36 to 0.68 . This instrument was also adapted and validated for the Brazilian context ${ }^{(11)}$, presenting good internal consistency; inter-item correlation, measured through Cronbach's alpha, was 0.86 .

The instrument was specifically conceived to determine six dimensions of self-care behavior among people with diabetes: general diet (two items), specific diet (three items), physical activity (two items), glucose blood testing (two items), foot care (three items), and medication (three items according to the medication scheme), in addition to three items concerning smoking.

This questionnaire addresses self-care activities performed by the patient in the last seven days. The assessment is standardized in days per week with scores indicating the performance in self-care activities on a scale from 0 to 7, corresponding to behaviors performed in the last seven days, in which 0 (zero) corresponds to the least desirable behavior and 7 refers to the most desirable behavior (except in the specific diet dimension, in which values are inverted). The items in the specific diet dimension address the consumption of foods rich in fat and glucose. As in the original instrument, scores in this dimension are inverted (if $7=0 ; 6=1 ; 5=2 ; 4=3 ; 3=4 ; 2=5 ; 1=6$; and $0=7$ and vice-versa) ${ }^{(12)}$. Smoking habits are considered separately because they are coded differently, with an emphasis on the average number of cigarettes smoked per day ${ }^{(12)}$.

The patients were recruited via telephone and invited to attend the PHC unit in which they were enrolled on scheduled days and times. The patients were informed in regard to the study's nature and objectives and showed their consent by signing free and informed consent forms. Data were collected in August 2012 in a private room in which the participants individually self-applied the instruments, which took 20 minutes on average.

Descriptive statistics was used to analyze data and to characterize the distribution of the responses of patients with DM. Because it is seven-point Likert scale, we need to consider the amplitude of distribution of responses. In this study, we considered desirable self-care behaviors the means of which were above 4 . The choice of this parameter is justified because it corresponds to the most desirable self-care activities. This cut-off point was also adopted for items with inverted values and is related to the number of days in a week on which the self-care activity was performed. In the analysis, we computed the mean and standard deviation for each item of the SMB's six dimen- sions. The project was approved by the Institutional Review Board at the University of São Paulo at Ribeirão Preto, College of Nursing (Protocol No. 418).

\section{QRESULTS}

In regard to the demographic variables, most of the patients were female, aged between 50 and 69 years old. In regard to education, most had not completed middle school. Clinical variables showed that $46.6 \%$ of the patients have had the disease for 10 years. In terms of comorbidities, most had more than one comorbidity, mainly hypertension and dyslipidemia. Concerning medication, most used insulin in the treatment. In regard to the number of medical appointments per year, most patients attended from one to four consultations per year with a physician.

Table 1 shows the self-care activities performed by the participants assessed through SMBG. Note that mean scores above 4 indicate desirable self-care behaviors, except for items with reverse values. When analyzing data in Table 1, one should bear in mind that it is a 7-point Likert scale and, considering this amplitude of answers, values from 0 to 4 indicate undesirable self-care activities, and from 5 to 7 indicate desirable activities, except for the items with inverted values.

Most of the patients in the SMBG program presented a desirable behavior in the General Diet dimension and complied with the recommendations of healthcare providers to "follow a healthy diet". When, however, this dimension was analyzed in the item "follow their diet plan", most presented an undesirable self-care behavior in this item.

The items in the Specific Diet dimension "Eating five or more portions of fruits and/or vegetables" and "Eating red meat and/or whole milk derivatives", the scores of which are inverted, revealed most patients presented desirable self-care behavior.

The items "Exercise for at least 30 minutes" and "Perform specific exercises", both in the Physical Activities dimension, showed undesirable self-care behaviors among the participants.

In regard to the dimension Blood Glucose Testing, the mean scores of the items "blood glucose monitoring" and "blood glucose monitoring as frequently as recommended" showed most patients presented desirable self-care behavior.

In regard to the Foot Care dimension, the items "Check your feet"and "Inspect inside your shoes before putting them on" show that most patients do not present these desirable self-care behaviors. Most, however, show desirable behavior in regard to "drying between toes after washing feet". 
Table 1. Self-care activities of patients enrolled in a self-monitoring blood glucose at home program assessed through SDSCA, Ribeirão Preto-SP, Brazil 2012.

\begin{tabular}{|c|c|c|c|c|c|}
\hline \multirow{3}{*}{ SDSCA items } & \multicolumn{4}{|c|}{ Frequency (days per week) } & \multirow{3}{*}{ Mean \pm SD } \\
\hline & \multicolumn{2}{|c|}{0 to 4 days } & \multicolumn{2}{|c|}{5 to 7 days } & \\
\hline & $\mathbf{n}$ & $\%$ & $\mathbf{N}$ & $\%$ & \\
\hline \multicolumn{6}{|l|}{ General diet } \\
\hline 1. Follow a healthy diet (D) & 33 & 44.0 & 41 & 54.7 & $4.41 \pm 0$ \\
\hline 2. Follow dietary recommendations (D) & 45 & 60.0 & 29 & 38.7 & $3.00 \pm 3.08$ \\
\hline \multicolumn{6}{|l|}{ Specific diet ${ }^{* *}$} \\
\hline 3. Eating five or more portions of fruits an/or vegetables (ND) & 36 & 48.0 & 38 & 50.7 & $4.24 \pm 2.69$ \\
\hline 4. Eating red meat and/or whole milk derivatives (ND) & 30 & 40.0 & 44 & 58.7 & $5.10 \pm 2.23$ \\
\hline 5. Eating sweets (ND) & 67 & 89.3 & 7 & 9.4 & $1.45 \pm 1.95$ \\
\hline \multicolumn{6}{|l|}{ Exercise } \\
\hline 6. Exercise for at least 30 minutes (D) & 55 & 73.3 & 19 & 25.4 & $2.05 \pm 2.53$ \\
\hline 7. Perform a specific exercise (D) & 66 & 88.0 & 8 & 10.7 & $0.89 \pm 2.03$ \\
\hline \multicolumn{6}{|l|}{ Blood glucose testing } \\
\hline 8. Assessing blood glucose (D) & 34 & 45.3 & 40 & 53.4 & $4.71 \pm 2.49$ \\
\hline 9. Assessing blood glucose as frequently as recommended (D) & 41 & 54.7 & 33 & 44.0 & $4.06 \pm 2.74$ \\
\hline \multicolumn{6}{|l|}{ Foot care } \\
\hline 10. Checking feet (D) & 43 & 57.3 & 31 & 41.4 & $3.29 \pm 3.18$ \\
\hline 11. Inspecting inside shoes before putting them on (D) & 39 & 52.0 & 35 & 46.7 & $3.59 \pm 3.26$ \\
\hline 12. Drying between toes after washing feet (D) & 22 & 29.3 & 52 & 69.4 & $4.97 \pm 3.11$ \\
\hline \multicolumn{6}{|l|}{ Medication } \\
\hline 13.Taking medication as recommended (D) & 4 & 5.3 & 70 & 93.4 & $6.58 \pm 1.35$ \\
\hline 14. Taking insulin shots (D) & 10 & 13.3 & 64 & 85.4 & $6.14 \pm 2.05$ \\
\hline 15. Taking the indicated number of anti-diabetic pills* $(D)$ & 13 & 17.3 & 56 & 74.7 & $5.63 \pm 2.59$ \\
\hline
\end{tabular}

* 5 patients did not take medications, ${ }^{* *}$ Reverse score, (D): desirable; (ND): not desirable

When the Medication dimension was considered, most patients presented desirable behaviors in regard to all the items assessed ("Taking medication as recommended"; "Taking insulin shots as recommended"; and "Taking the indicated number of anti-diabetes pills").

Table 2 presents the results obtained in the items related to smoking habits. Most of the patients had not smoked in the last seven days, with an expressive number of former smokers and people who never smoked before.

\section{DISCUSSION}

The analysis of self-care activities performed by patients enrolled in a self-monitoring blood glucose program and using, for the first time in the Brazilian context, a spe- cific instrument, showed that effort is required to monitor individuals with diabetes. The results revealed that patients recognize the importance of diet, exercise, monitoring blood glucose and foot care, but require continuous effort to achieve the goals established for the management of the disease from the perspective of diabetes education.

The analysis of the General Diet dimension showed that patients with DM presented desirable self-care behaviors in regard to complying with a healthy diet. One study shows that difficulties for and barriers to the modification of eating habits are known and include: negative perception concerning diet plans; barriers in regard to social events; and lack of knowledge and understanding of the importance of having a healthy diet as a pillar of the treatment of diabetes, such as: regular hours and smaller meals, 
Table 2. Smoking habits in the studied sample, according to items in the Summary of Diabetes Self-Care Activities Questionnaire (SDSCA). Ribeirão Preto-SP, Brazil 2012.

\begin{tabular}{|c|c|c|c|}
\hline SDSCA items & \multirow{2}{*}{ Frequency } & \multirow{2}{*}{$\mathbf{n}$} & \multirow{2}{*}{$\%$} \\
\hline Smoking & & & \\
\hline \multirow{2}{*}{ Have you smoked in the last seven days? } & No & 67 & 89.4 \\
\hline & Yes & 7 & 9.3 \\
\hline \multirow{7}{*}{ When did you smoke your last cigarette? } & Never smoked & 42 & 56.0 \\
\hline & More than two years ago & 21 & 28.0 \\
\hline & From one to two years ago & 2 & 2.6 \\
\hline & From four to 12 months ago & 1 & 1.3 \\
\hline & From one to three months ago & 1 & 1.3 \\
\hline & In the last month & 0 & 0 \\
\hline & Today & 7 & 9.4 \\
\hline
\end{tabular}

Source: Study's data.

and the relationship of eating with the use of medication and exercise, among other aspects ${ }^{(13)}$.

Difficulties were observed regarding compliance with the diet plan, which may be explained, in part, by a lack of nutritionists in the multidisciplinary teams in the two studied PHC units. A lack of this type of professional impedes patients with diabetes from discussing, sharing and developing a diet plan that meets their needs concerning preferences and costs. One study conducted with DM patients who experienced complications in their lower limbs reports means higher than those presented in this study ${ }^{(2)}$.

We need to consider that eating habits are already established in adult individuals and are maintained by a set of beliefs and values already incorporated over the course of life ${ }^{(7-8)}$. Therefore, assessing self-care activities is always a difficult and complex task. Often, changes in a diet plan may be desirable from the point of view of healthcare providers but not feasible from the perspective of patients.

The Specific Diet dimension showed that patients with DM present undesirable behavior related to the excessive consumption of foods such as red meat and whole milk. We expected a predominance of patients with desirable self-care behavior, since recommendations regarding diet are basic and have a direct effect on blood sugar. These results are also reported by one study conducted in India with DM2 patients, which confirms that self-care activities concerning diet fall short of what is ideal in regard to the restriction of simple carbohydrates, which are immediately absorbed.

The Physical Activity dimension showed that patients do not recognize this therapeutic resource as an activity incorporated into their self-care actions. Hence, the results show that patients with DM do not incorporate exercise into their self-care activities, which is in agreement with the results of studies conducted both in China and India ${ }^{(1,3)}$. This situation may reflect a lack of recommendation on the part of health providers for this mainstay of DM treatment. Other factors that may explain this undesirable behavior include a risk of hypoglycemia during exercise and orthopedic problems that hinder the practice of exercise, among other factors ${ }^{(10)}$. One study conducted in India verified that self-care activities concerning exercise are below the ideal level(3). One study conducted in China reports that $56 \%$ of the investigated sample performed some exercise, either as a leisure activity or not, and only 4\% were considered very active $^{(1)}$. One Brazilian study conducted with DM2 patients with low education and income, who had DM for a long time, presented low adherence to self-care actions such as exercise and diet ${ }^{(4)}$.

One systematic review identified that most people with DM self-manage the disease, but there is variation in how well they adhere to the main self-care activities. The levels of exercise do not change over time. Evidence suggests that the pattern of response to exercise changes in response to many factors, such as vacation times, holidays, and weekends, suggesting the need for further studies to clarify this issue ${ }^{(14)}$.

Most patients with DM presented desirable behavior in regard to the items "testing for blood glucose" and "testing for blood glucose as frequently as recommended", which shows that patients enrolled in the SMBG program are verifying their blood glucose at home, as prescribed. 
One study conducted in India reports that self-care activities related to SMBG were considered appropriate ${ }^{(3)}$. One Chinese study showed that only 13\% of the 163 participants presented desirable behavior regarding SMBG and only $3 \%$ tested it four or more times during the week ${ }^{(1)}$. Another study investigating the experiences of patients with glucose testing shows that this dimension of self-care benefits and favors decision-making that results in managing the disease $\mathrm{e}^{(15)}$.

Difficulties of patients with DM to make decisions concerning SMBG due to insufficient education to read and properly interpret data should be taken into account. In this sense, educating patients to self-monitor their glucose is a challenge for healthcare providers, who should seek innovative strategies ${ }^{(16)}$. At the same time, nurses need to be qualified to motivate patients to recognize the monitoring of blood glucose as an important tool in self-care ${ }^{(17)}$.

If nurses are not trained to work in the SMBG program, the resources provided to patients to monitor blood sugar at home (glucometer, lancet, test strips, etc.) might be underutilized or misused. This suggests that simply providing supplies does not ensure they will be properly employed ${ }^{(3)}$.

Most of the patients did not present desirable behavior in regard to foot care. One study, though, in which patients received educational instruction in a large hospital in a city of São Paulo, Brazil reports scores close to desirable levels in the three dimensions concerning foot care, indicating the importance of education to modify health behavior ${ }^{(2)}$.

The best result was found in the Medication dimension, in the taking medication as a recommended item ${ }^{(10)}$. The behavior "taking insulin shots as recommended" shows patients have difficulty taking the recommended dosage at the recommended times. In regard to the number of oral anti-diabetes pills, a minority was unable to take the recommended number of pills some days in the week. One Chinese study shows that most participants presented very desirable self-care behavior concerning adherence to medication $^{(1)}$.

In regard to smoking habits, this study shows that there is an incorporation of self-care regarding smoking, considering that smoking is a risk factor for the development of diabetic neuropathy. This study's results are consistent with those reported by another study that investigated smoking using SDSCA among DM patients with complications in their lower limbs ${ }^{(2)}$.

We expected that the self-care behaviors concerning specific diet, physical activity and self-monitoring of blood glucose would reach highly desirable levels, considering the participants were enrolled in an SMBG program in a PHC unit in a city of the state of São Paulo. Nonetheless, the results obtained concerning self-care behavior in SDSCA's six dimensions were below desirable levels, showing the need to develop effective educational strategies to strengthen self-care practices among diabetes patients participating in SMBG programs.

Identifying self-care activities using an instrument specific for the population with diabetes enabled verifying that there is a weakness in the educational process, since the participants were already enrolled in the SMBG at home program. The few studies using SDSCA to assess self-care activities among patients with diabetes limited the comparison of data, hindering the establishment of similarities and differences. We expect that future studies will allow a better understanding of self-care activities of patients with DM.

Finally, the modification of self-care actions among patients with diabetes includes cooperation within the health staff, supply of resources, the development of alternatives that include family members and other people from the patient's social network and social organizations.

\section{$\square$ CONCLUSION}

The analysis of specific self-care activities of DM patients enrolled in an educational group for SMBG at home revealed that eight of the 15 assessed self-care activities were within desirable levels, namely: healthy diet, not eating sweets, testing blood glucose as frequently as recommended, drying between toes after washing feet, and taking medications (three items). These results can support the reorganization of the SMBG program in the city because non-adherence of patients to self-care activities may compromise the effectiveness of the program and hinder the achievement of metabolic control. Assessing specific self-care activities provides valuable elements for nursing professionals as agents who primarily coordinate educational groups in diabetes, encouraging the reformulation of educational practices concerning SMBG. Healthcare practices should strengthen desirable self-care practices. The educational process is difficult, continuous and permanent, requiring the use of innovative strategies to achieve the goals related to controlling DM, since the modification of habits and behavior demands changing feelings, emotions, rooted beliefs.

\section{REFERENCES}

1. Zhou Y, Liao L, Sun M, He G. Self-care practices of Chinese individuals with diabetes. Exp Ther Med. 2013;5(4):1137-42.

2. Gomides DS, Villas-Boas LCG, Coelho ACM, Pace AE. Self-care of people with diabetes mellitus who have lower limb complications. Acta Paul Enferm. 2013;26(3):289-93. 
3. Gopichandran SV, Lyndon MK, Angel PB, Manayalil BP, Blessi KR, Alex RG et al. Diabetes self-care activities: a community-based survey in urban southern India. Natl Med J India. 2012;25(1):14-7.

4. Villas Boas LCG, Foss MC, Freitas MCF. Relação entre apoio social, adesão aos tratamentos e controle metabólico de pessoas com diabetes mellitus. Rev Latino-Am Enfermagem. 2012;20(1):52-8.

5. Secretaria Municipal da Saúde de Ribeirão Preto (BR). Protocolo de atendimento em hipertensão e diabetes [Internet]. Ribeirão Preto; 2011 [citado 2014 mar 17]. Disponível em: http://www.ribeiraopreto.sp.gov.br/ssaude/programas/ cronico/prot-hipertensao.pdf

6. Organización Panamericana de Salud. Fortalecimiento del autocuidado como estratégia de la atención primaria en salud: la contribuición de las instituiciones de salud en America Latina. Santiago; 2006.

7. Rodrigues FFL, Zanetti ML, Santos MA, Martins TA, Sousa VD, Teixeira CRS. Conhecimento e atitudes: componentes para a educação em diabetes. Rev Latino-am Enfermagem. 2009;17(4):436-73.

8. Oliveira NF, Souza MCBM, Zanetti ML, Santos MA. Diabetes mellitus: desafios relacionados ao autocuidado abordados em grupo de apoio psicológico. Rev Bras Enferm. 2011;64(2):301-7.

9. Baquedano IR, Santos MA, Martins TA, Zanetti ML. Self-care of patients with diabetes mellitus cared for at an emergency service in Mexico. Rev Latino-Am Enfermagem. 2010;18(6):1195-202.
10. Faria HTG, Rodrigues FFL, Zanetti ML, Araújo MFM, Damasceno MMC. Fatores associados à adesão ao tratamento de pacientes com diabetes mellitus. Acta Paul Enferm. 2013;26(3):231-7.

11. Michels MJ, Coral MHC, Sakae TM, Damas TB, Furlanetto LM. Questionário de atividades de autocuidado com diabetes: tradução, adaptação e avaliação das propriedades psicométricas. Arq Bras Endocrinol Metabol. 2010;54(7):644-51.

12. Bastos F, Severo M, Lopes C. Propriedades psicométricas da escala de autocuidado com a diabetes traduzida e adaptada. Acta Med Port. 2007;20(1):11-20.

13. Booth A0, Lowis C, Dean M, Hunter SJ, McKinley MC. Diet and physical activity in the self-management of type 2 diabetes: barriers and facilitators identified by patients and health professionals. Prim Health Care Res Dev. 2013;14(3):293-306.

14. Coyle ME, Francis K, Chapman Y. Self-management activities in diabetes care: a systematic review. Aust Health Rev. 2013;37(4):513-22.

15. Dlugasch $L B$, Ugarriza DN. Self-monitoring of blood glucose experiences of adults with type 2 diabetes. J Am Assoc Nurse Pract. 2013;18:1-7.

16. Evans JM, Mackison D, Swanson V, Donnan PT, Emslie-Smith A, Lawton J. Self-monitoring of blood glucose in type 2 diabetes: patients' perceptions of 'high' readings. Diabetes Res Clin Pract. 2013;102(1):e5-7.

17. Schöld AK, Ylikivelä R, Lindström K, Östgren CJ, Grodzinsky E. The options of the management of self-monitoring of blood glucose in primary health care centres by the diabetes nurses and patients. Prim Care Diabetes. 2013;7(2):143-9.

\section{Author's address:}

Maria Lucia Zanetti

Av. Bandeirantes, 3900, Monte Alegre

14040-902, Ribeirão Preto, SP

E-mail: zanetti@eerp.usp.br
Received: 10.06.2014

Approved: 10.11.2014 